\title{
Government functions and role analysis in sports industry and tourist industry integrative development
}

\author{
Bing Zhang ${ }^{1, a}$, Kunling Qin ${ }^{2}$, Qian Yang ${ }^{1}$ and Zhisheng Liu ${ }^{1}$ \\ ${ }^{1}$ Institute of Physical Education, Huanggang Normal University, Huangzhou 438000, China \\ 2 Yidu Gaobazhou Middle School, Yidu 443300, China
}

\begin{abstract}
In the era of economic globalization, industry integration trend becomes more obvious, industry integration phenomenon raises new topics to industry classification and industrial organizational theory, and meanwhile it also raises new problems and challenge to government formulated relevant industrial regulation and policies. In sports industry and tourist industry integrative development, government role positioning is crucial. By literature research method, interdisciplinary research method and other methods, it collects relevant information about sports industry and tourist industry integration, as well as government respective published relevant policies and reform system for sports industry and tourist industry in development procedure. The paper mainly researches delimitation of sports tourism concept, delimitation of industrial integration concept, governmental regulation and role positioning definition, analyzes recent years sports industry and tourist industry development trends, governmental regulation reform's impact on the two integrative development and positioning of government role. Analysis result shows that due to tourism and sports coupling in essence, Chinese tourist industry and sports industry convergent trends become more and more obvious, but the two will appear conflicts in integrative process due to rule, resources and benefit distribution differences. Therefore, only regulate effective government supportive policy then can propel to sports and tourist industry integration further improvement, and accurately seize governmental regulation changes rules and features, formulate regulation systems with rationality, forward looking and scientificity to provide feasible schemes for sports industry and tourist industry sustainable development.
\end{abstract}

\section{Introduction}

Regarding industrial integration discussion, it started in the end of seventies, 20th century, technical development under traditional technical revolution pushing and traditional industrial production manner led to long term existence of industrial separation form with clearly industrial boundary. Industrial integration endowed new connotation to industrial economy and its theory, and also reflected entire new era integration process. Industry is "common composed by enterprises that provides approximate goods or services and move in the same or relevant value chain, and of some commonalities that is base for classifying enterprises into different industries."Integration is "moving towards one point or convergence of two or more elements, or integrating several different things into one."Chinese industrial integration field authority $\mathrm{Li}$ Wu-Wei thought," industrial integration referred to dynamic development process that different industries or different products in one industry interpenetrated, intercrossed and finally fused together, gradually formed into new industries". Japanese economist Masu Uekusa thought, industrial integration was using technical innovation and limitation extension to reduce barriers among industries to strengthen competitive cooperative relationship among industries enterprises [1-4].

Regarding systems that affected industrial integration, $\mathrm{Wu}$ Ying and others pointed out that enterprises competition and cooperation stress, market demands impetus, technical innovation and diffused tension, governmental regulation loosen supporting force and other four aspects had impacts on industrial integration forming. Xing Zhong-You put forward that from the perspective of institutional economics, sports tourist industry integration was an institutional changing process under government-leading. Therefore, during sports industrial development and tourist industrial development as well as the two integrative development process, government played a certain leading and pushing roles, in diversified development process, state government adopted corresponding measures to let sports tourist industry and other industries benefits to gain balanced guarantee, however because of industries barriers and certain institutional barriers in the process, it would let sports tourist industrial development to confront many hinders, especially for benefit, resource allocation problems, and would cause enterprises mutual conflicts, and so state

${ }^{a}$ Corresponding author: tiyuxi@qq.com 
government should devote greater effort to carry out corresponding institutional reform, adopt feasible schemes to solve the problem [5-7].

By analyzing formers' researches on sports tourist industrial integrative development, presently sports industry and tourist industry integrative development policies and system environment became the largest bottleneck of their development, but relative literature hadn't yet specially studied sports industry and tourist industry integrative relevant governmental regulation, and had not mentioned systematic, reasonable, scientific and effective solutions. Based on above facts, the paper mainly based on formers' researches about sports and tourist industry, it further researches on government role positioning in sports industry and tourist industry integrative development process, highlights government behaviors impacts and significances in sports industry and tourist industry; further promotes industrial integration theoretical system establishment to provide policies suggestions and decisions basis for further driving and perfecting sports industry and tourist industry integrative development. For these problems, state and government hadn't yet formulated specific solutions, so the main purpose of the article is researching on government role positioning affects and significances in sports industry and tourist industry integration, letting government to formulate feasible policies, giving its effective functions into play, thoroughly solving problems in the integration of the two, propelling to sports industry and tourist industry sustainable development. Sports industry and tourist industry integrative development is of important industrial values to propel to social prosperity, spiritual civilization, the two main industries respective development and even Chinese livelihood service industry overall development, so research on the two main industries integration is of theoretical and practical significance in implementing state policies and guiding industries practice [8].

\section{Research Objects and Methods}

\subsection{Research objects}

The article researched main objects are sports industry, tourist industry and government.

\subsection{Research methods}

Literature research method, through school library and online consulting, relevant literature data collecting and analytic sorting, it provides firm theoretical basis for the paper researches.

Interdisciplinary research method, the paper gets involved in sports industry and tourist industry such two disciplines relative information, as well as government systems and other relevant legal provisions, so it need to well handle the three interrelation, and crossed go ahead with analytic researching [9].

\section{Sports industry and tourist industry development history and current situation analysis}

\subsection{Combing the concept}

Sports tourism as a kind of newly fitness entertainment activity way, it attaches great attentions of sports circle and tourism circle. In China, sports industry and tourist industry integrative development is of important impacts on driving Chinese economy and social long-term development. Regarding sports tourism definition, it hasn't yet clearly defined; the paper mainly lists following types: Min Jian thought that sports tourism was a kind of tourist activity way that people aim at visiting and watching sports movements or regard sport as main content. Jiang Fu-Gao thought that sports tourism was social cultural education activities that people had all relationships with sports tourist places, sports tourist enterprises and society by using leisure time, temporarily leaving residence place on the premise of non-profit, with the help of each kind of sports ways and final targets of physical and psychological harmonious development, enriching social cultural life, propelling to spiritual civilization. Cang Jing-Liang and others thought that sports tourism was the sum total of people's foreign country tours out of residence places and lingering activities with sports demands or sports interests and other sports relative motivations (fitness, entertainment, leisure, opening the mind, participating in or watching games and so on), as well as these activities generated people, place, thing the three relationship and these relationship caused phenomena. Song Jie and others thought that sports tourism was a kind of social cultural activity that visitors relied on tourist places natural environment, humanistic environment to fulfill sports experiences during tourism process.

By comprehending above concepts, sports tourism is a newly-typed industrial activity that sports industry and tourist industry organize and crossed integrate with sports resources as intermediary. Sports industry and tourist industry gain high speed development, except for meeting people demands and is well favored by enterprises and masses, it mainly is on account of government relevant regulation to ensure industrial stable development.

For government regulation definition understanding disputes, foreign scholars expressions are different: Viscusi and other scholars thought that government regulation was a kind of mandatory limit that government implemented on individuals or organizations' free decision-making in the way of sanction. Spulber thought that government regulation was a general rule or special behavior that administrative organization formulated and implemented direct intervention market mechanism or indirect changed enterprises and consumers' supply and demand policies. Japanese scholar Masu Uekusa limited government regulation in the limiting behaviors when defined government regulation, he thought government regulation was a behavior that public institution (generally referred to 
government) conducted on enterprises activities according to certain rules.

Samuelson also limited government regulation in the limitation that government conducted on industrial behaviors. However, Stiglitz expanded regulation into more broad range, he thought government protection, supporting and rationalization and transformation on industries, all of which could be regarded as government micro regulation scope. Maier thought regulation referred to trials that government controlled citizens, companies or subordinate government behaviors, which referred government limitation on citizens' selection in social scope to some sense.

Synthesize above scholars discussion, I define government regulation as government adopted all kinds of actions and measures with legal force on economic subjects by utilizing compelling force such resource to fulfill social economic targets.

\subsection{Chinese sports industry development history's government roles review}

According to early stage's scholars' researches and conclusions, it is clear that the beginning of Chinese sports industry started after the third Plenary Session of the 11th Central Committee of Chinese Communist Party, the causes was that Chinese economic development gradually improved, social openness was increased, people started to focus on sports activities since the third Plenary Session of the 11th Central Committee of Chinese Communist Party, but sports relevant sections hadn't yet formulated perfect and reasonable systems and standard mode for sports events and sports activities, functions as guiding, coordinating, monitoring and others hadn't been fully reflected, so sports industry hadn't formed. Under this circumstance, the Central Committee of the Communist Party of China made decision on sports system reform, and successively released "Notice on further developing sports" and "Decision (draft) on sports system reform" the two important files through the Central Committee of CPC and National Sports Commission to promote sports socialization, scientification and propel to sports all-round development and improvement reform.

Therefore, national sports commission put forward "gradually realized stadiums facing to masses, society on the basis of priority ensuring sports undertaking development, and transited from administrative management type to economic operation type; developed multiple operation modes and extension ways, improved stadiums using rate, gradually arrived at self-financed, used stadiums to manage stadiums on the premise of ensuring sports activities normally organizing." It let policy of stadium's "sports majored, multiple operated" to be gradually implemented, provided precious suggestions for Chinese local vigorously stadiums construction, and let sports resources to gain sufficient and reasonable application; secondly, the State government vigorously promoted Chinese competitive sports socialization. It encouraged professional teams to cooperate with enterprises, advocated sports competition and economic operation activities jointly carried out, and formed into socialized features as "internal introduced and external jointed", "Sports set stages and economic trade played". The reform opened up sports team sponsoring enterprises situation, promoted increasingly emerging of all kinds of entities, and propelled to industries, enterprises benefits to gain balanced development.

National sports commission held Zhongshan meeting about discussing sports system reform in 1992, and subsequently issued "Decision on deepening sports reform", put forward reform total target as "establishing individual developing vigorously sports system and virtuous cycled operational mechanism that was adapted to socialist market economy, conformed to modern sports movement rules, national adjustment and controlling, relying on society, formed into situation of combination of state organized and social organized, joint of concentration and dispersion, and submitted sports industries problems into agenda as one of important problems in deepening sports system reforms. Nationwide sports commission directors meeting formulated "Opinions on fostering sports market, speeding up sports industrialization process" in 1993, it defined basic thought that sports should "face to market, walk toward market and be industrialization-oriented". National sports commission also issued "Sports industry development outline (1995-2010)" in 1995, it pointed out that Chinese sports industry three types were sports main industry, sports relevant industry and sports managed industry. The Fourth Session of the Eighth National People's Congress approved "Outline on National economy and social development "the ninth five year" plan and prospect targets in 2010" in 1996 further clearly required that "sports should form into situation that state and society commonly set up sports, take the road of socialization and industrialization". By state government successive published relevant policies, it let sports industry to rapidly and stable develop, all sports competition markets, sports lotteries exploitation, as well as the hosting of Chinese sports products expo, all highlighted state policies supporting force and functions on sports industry development.

Beijing won the hosting right of the 29th Olympic Games in 2001, comrade Hu Jing-Tao during his speech of 2008 Beijing Olympic Games, Paralympic Games summary commendation congress, he clearly summoned "it should further promote China to move from main sports country to sports power". With the successful hosting of Beijing Olympic Games in 2008, it propelled to Chinese economy, politics, culture and others prosperity situation, and meanwhile it brought new opportunities to Chinese sports industrial development. In order to develop sports industry for a long term, popularize sports product, consolidate sports industry position, it successively held two sessions nationwide sports industry working conference in 2005 and 2007, which respectively put forward important development thoughts as "sports industry together with mass sports, competitive sports were important parts in Chinese sports undertaking" as well as "sports industry was definitely not only sports section itself established industry but also the sports industry as one part 
of social economic life that was whole society's sports industry" and others. In July, 2005, General administration of Sport of China issued "Sports undertaking " the 11th five year" plan" also clearly presented "the 11th five year" period Chinese sports industry development target that was "initially established sports industry system to adapt to mass consumption level, centered on sports service industry, multiple industry simultaneously integrated, complete ranged, reasonable structured and standard developed, formed into situations that multiple ownership co-existed, whole society common participated, and common set up." And meanwhile, General administration of sport of China also held sports service identification, the national games market development, sports service standardized working, sports industry statistics, state sports industrial bases construction and others multiple sports industrial works, by continuously efforts of all circles of society, government functions sufficient playing, it propelled to Chinese sports industry development, guaranteed economic society rapid development.

Reviewed sports industrial development history, presently Chinese sports industry development current situations mainly reflected in following aspects: firstly, sports market began to take shape, and formed into relative perfect sports market system. The emerging and development of all kinds of sports markets increasingly enriched people's life, and fitness entertainment market that took main market position always attached people's attentions, was the consumption market of broad masses participation. Since the first session of sports goods expo successful hosting in 1993, Chinese sports goods market gradually expanded production scale, broke through original production situation to build good basis for propelling Chinese economic development. Secondly, the exploitation fields continued to expand, and economic efficiency continued to increase. Local sports sections and tourism sections continuously exploited and mined sports tourist resources according to local features and differences, and sufficiently utilized sports tourism resources, increasingly accumulated sports assets and tourism assets, and then drove local economic development. The measures were legitimate and also necessary. It not only gradually expanded sports assets scope, but also rationally carried out resources effective allocation and further drove economic development.

Sports industry as Chinese emerging industry that grew gradually, although it was favored by public and focused by enterprises, some problems still existed in its development, which affected sports industry normal development to a certain degree. Firstly, Chinese sports industry development was still backward by comparing to foreign developed cities, sports market development was immature, sports market scale was small. Whether sports market system was perfect and reasonable or not was totally up to state government dominating forces, and meanwhile, sports market suffered a lot of internal and external factors affects in development process, such as environment, capital, resource, human resources to different degrees. In recent years, sports market had begun to take shape through continuous improving operational structures and adjusting development planning, however, its level was still lower that needed to reinforce and improve so as to propel to its better and faster development. Secondly, sports industrial structure was not perfect and reasonable enough, due to Chinese systems, state government was main investor and advocator in guiding sports undertaking development, government drove sports industrial development through raising capital, issuing and implementing relevant policies and other measures so that meet social members sports demands, but some government officers only focused on sports investment fields and projects of appearing and sensational effects for the pursuit of their own benefits and improving their working performances in official careers, while didn't adopt proactive and effective measures to sports projects that were slowly developing and of no attentions. Due to Chinese society reflected dual structure, sports industry development also suffered certain affects; therefore sports industrial structures' contradictions were quite prominent. Thirdly, high-quality sports economic operation typed talents lacked of operational awareness, sports theoretical knowledge and scientific operational methods, it restricted sports industrial development. Fourthly, sports market management normalization and institutionalization were to be improved. Standardized and orderly market was an important premise for ensuring economy stable and continuously development, though presently local governments issued corresponding management plans, it still was short of clearly functions divisions, management rights clearly classification, enforcement procedures perfection and unification and so on. Therefore, state government needed to publish relevant sports industrial management policies and regulations as soon as possible to thoroughly solve such problems.

\subsection{Chinese tourism development history's government role review}

Since reform and opening-up, through state government vigorous supporting and leading, it let tourism gradually to go ahead on track, its economic development was thriving, which vigorously drove Chinese tourism overall scale and quality promotion, propelled to economic structure reasonable adjustment. During 20 years from 1985 to 2005 , nationwide 31 provinces, cities, municipalities' local governments totally issued over 60 "Decisions", it composed of policies system that Chinese local government developed tourism, the paper selects ten provinces, cities and municipalities to carry out researches and analysis of evolution tracks that local government propelled to tourism development in 20 years.

From relative analysis, it was clear that local government implemented relative policies for propelling to tourism development was of certain promotion, it sped up Chinese tourism development to a certain degree, and regarded tourism as important pillar industry in China's national economy development, local governments implemented measures mainly concentrated on the fields of fiscal policies supporting, financial policies supporting, tax policies supporting and else. As local government, it started from local practical economic environment and potential 
exploitation; the formulated policies had a certain rationality and practicability that built good foundation for state tourism economy long-term continuous development, but on the other hand, due to regional differences and economic development degrees differences, state government "Decision" contents, policies implementation, targets systems and other aspects would have differences, the final promotion would also obviously different. But in recent years, state government successively published relevant policies and regulations to support assist and develop tourism; Chinese tourism gained long-term development, no matter in the number of people took inbound and outbound tourism, tourist income or tourism position, all gained great development and improvement. By implementing government regulation, it could play pushing roles in tourism development to a certain degree. In "Opinions on speeding up developing tourism" that published by the State Council in December.25th, 2009, it put forward "tourism basic facilities and key tourist projects construction should be brought into national economy and social development plans in formulating nationwide tourism development plan; and set China's tourism holidays in formulating national tourism relaxation outline. Implemented paid leave system, firmly grasped tourism comprehensive legislation, sped up formulating tourism market monitoring, resources protection, occupational standards and other specialized legal regulations, continued to perfect relevant laws and regulations, perfected mating policies and measures." And meanwhile, National Tourism Administration formally issued "Nationwide tourism standardized development planning (2009-2015)", after that it was amended in 2009, and established standard system frame that majored in tourism six main elements that played important driving roles in propelling to tourism sound development.

So far, tourism had become one of important national people's life style, and become an industry of huge consumption potential, good growth efficiency. But tourism as emerging industry, its growing time was shorter, industrial structure was in urgent need of adjustment, comprehensive mating was weaker, tourist products types exploitation, tourism mode innovation and else, all would affect tourism development that still needed state government policies supporting; secondly, tourism as economic industry, it would suffer many internal and external factors affects, as market mechanism, market demands, system, capita, manpower and so on, so tourism needed to combine with market economic mechanism to formulate proper development plan and extension ways in development process to guarantee its development to adapt to economic development trend, and meanwhile, for industrial layout, industrial organization, industrial guarantee and other problems, all still needed state government policies to adjust; thirdly, tourism as comprehensive industry, it had certain correlations with other industries, which surely would suffer other industries influences, therefore while reasonable solved its own industrial problems, it also should consider other industrial factors influences, let industries multiple benefits to gain balanced and coordinated development, and it still needed government powerful supporting and preferential policies to realize win-win situation.

\section{Sports industry and tourism integration's government roles positioning analysis}

\subsection{Chinese sports tourism integrative development history's government roles review}

General administration of sport of China, National Tourism Administration jointly issued "Initial written proposal about propelling to Chinese sports tourism development" in December.10th, 2009, it presented that " tourism section and sports section scientific schemed, strove for practicing, innovated sports tourism integrative development system mechanism, proactively explored working ways and methods to impel development, researched on relevant policies measures, and guided sports tourism sound development." The policy clearly defined the intention of jointly pushing sports tourism development, propelled to sports industry and tourism coordinated development that moved forward first step for realizing development strategic target of Chinese sports tourism construction reinvigorating China. "2010 China's sports tourism expo "successful hosting in Haikou, the fourth session China's sports tourism expo was an expo that general administration of sport of China and national tourism administration founded for further impelling sports industry and tourism mutual integration and common development, during the period of expo, it held "2010 China's sports development forum". The hosting of the forum propelled sports industry and tourism integrative development, affirmed that the integration of the two was specific reflection of adaptation to era development, therefore, it also regarded industrial integrative development as an important path and direction to propel to industrial long-term development in new period. In "sports industry "the 12th five year "plan", it presented "propelling to sports industry and relevant industry interactive development, giving sports industrial comprehensive effects and driving functions into play, putting emphasis on sports tourism and sports exhibition, driving sports industry and relevant industry compound operation, impelling sports tourism, sports expo, sports culture, sports publishing, sports media, sports creativity and other relevant commercial activities development".

Though China's sports tourism presently was still in the starting stage, it was rapidly developing at the speed of $30 \%-40 \%$ per year. In China's sports tourism rapidly development, it appeared sports tourism integration such a phenomena. Sports tourism essentially was the product of industrial integration, when the phenomena of industrial integration occurred, it surely would appear some output results output ways to be expanded to above two types that output results corresponding output ways increasing status. 


\subsection{Sports industry and tourism industry integration's government behaviors}

With the maturing of industrial development, government roles and functions would also change accordingly. By sports industry and tourism development history's government roles analysis and government roles converting recognition, government should undertake decision-maker, server, monitor and others multiple roles in the two main industrial integrative process and environment, therefore, government should fully learn factors that affected industrial development as economy, culture, techniques and so on, and on this basis, through giving government public opinions guiding role and social publicity roles into play, it expanded sports industry and tourism industry integration impacts, raising each level government, each enterprise and mass attentions to sports tourism integration to stimulate all circles initiatives of proactive participation. Besides, by government implementing relevant preferential policies, fostering model demonstration and other measures, it fully gave government guiding roles into play, created good industrial policies environment, promoted sports industry and tourism sound and continuous development.

\subsection{Present sports industry and tourism integration's government behaviors absence}

At present, sports industry and tourism integrative development was slower, though government grasped industrial integration development trend in the level of decision-making, the practical recognition and action on how to proceed with the two main industries deepen integration was little, problems mainly reflected in the two man aspects: firstly, weak government leading, decentralized right, and large scope cross regions industrial resources allocation caused local government functions resetting, and meanwhile, sports section and tourism section labor division was not clear that let sports resources and tourism resources management to have functions crossover and overlapping phenomena; secondly, in the preliminary stage of the two main industries integration, by integrating in the respective industrial policies, it continued to break through boundary between the two main industries, and through market, resource, techniques, products and others continuous alternating integration, it formed into sports tourism with new connotations, in industries each integrating phases, good system criterion and system links were necessary, but presently relative specific relevant policies and legal systems targeted at the two main industries integration each link hadn't yet published, more was file contents and guiding opinions in macro level. Therefore, government still had absence and drawbacks in these aspects.

\section{Chinese sports industry and tourism integrative development's government regulation implemented countermeasures}

Sports tourism was modern new typed tourism after ecological tourism. But sports tourism industry development was still in the primary stage, it needed government, enterprises and society common participation, especially for government driving force in sports tourism that was more beneficial to sports tourism industry continuous development. Therefore, government should design policies reform direction and path according to present sports tourism integrative development features.

\subsection{Make the importance of government role positioning in sports tourism integrative development clear}

Sports tourism development could drive social economic development to a certain degree, meet people increasingly growing material cultural demands, and help state to ease presently tight employment status, but whether the two could gain long-term development, it mainly was up to state government, what kind of roles that government acted, which kind of functions it played, essentially it related to sports tourism continuous, sound, stable development or not. Therefore, government should increase promotion to sports tourism that was crucial, and the driving function would exist for a long-term and continue to give positive roles into play. But in the perspective of practical perspective, government regulation implementing forces was far from enough, which required Chinese government to highly focus on sports tourism integrative problem, make clear targets at sports tourism integrative development, and formulate sustainable operation mechanism.

\subsection{Establish and perfect scientific and reasonable government regulation}

Formulation of government regulation was a double-edged sword, it was possible to propel to sports tourism integrative development and also hinder its development, and meanwhile, government regulation played "catalyzer" roles in sports tourism development, it could decide sports tourism development path, change sports tourism development track, so formulating perfect and reasonable government regulation system was crucial. Due to China's government hadn't laid enough emphasis on sports tourism and relative sections in the past, it let sports tourism resources to be heavy damaged, awareness of protecting sports tourism resources to be poor, in addition, due to large and small enterprises investment on sports tourism to be certain blind, corresponding local governments lacked of scientific evaluation system, disorderly exploitation and destructive exploitation, blind construction and repeatedly construction, which not only wasted sports tourism resources, but also caused extinction of non-renewable resources. Therefore, inexhaustible motivation that propelled to Chinese sports tourism to back on track was reasonable and scientific government regulation. State and government should highly focus on sports tourism integrative development impacts on environment and society, give state and local governments functions into play so that better define government role positioning. 


\section{Conclusions}

Sports tourism integrative development conformed to era development trend, was a formed new industry that sports and tourism targeted at cooperation and win-win in new periods, promotion to sports tourism integrative development should well handle sports tourism economy, sports resources and sports tourism environment relations, on which it could have an adjustment and safeguarding impacts were government functions and relevant policies systems. Effective government regulation system was basic guarantee for impelling the implementation of sports tourism integrative development, reasonable government regulation could propel to newly typed industries forming and developing, could reasonable allocate industries benefits and resources distribution, with economic effectiveness that sports tourism integrative development brought, state government started to lay highly emphasis on it ; for problems and conflicts appeared in industrial integration, government needed to see clearly facts, reset, correctly find solutions and directions. Development of sports industry and tourism was a government transitional procedure, in the long rough development process, government should create a good environment that was fit for industry development, and internal requirements in sports tourism integration would propel to government continuous innovation to adapt to newly typed industries, sports tourism should correspond to integrative regulation institutions and regulation policies. On the contrary, if sports tourism industries boundary changes couldn't make corresponding adjustment with government regulation system and regulation policies, it would be disjointed with facts. In sports tourism integrative development process, it should always adhere to government guiding position, recognize government multiple roles promotions to push industrial integrative development. It included continuous propelled to government regulation reforms, rechecked current regulation systems and regulation policies, established effective regulation systems to propel to sports tourism integrative development with forward looking and scientificity, and formulated corresponding regulation policies. Except for making clear its own importance, government should drive large and small enterprises and social groups to common participate in sports and tourism integrative development management group, let relative dynamic factors to common drive industrial integrative development, correctly grasp government and industries development rules and features, let government to find problems in time, make clear which roles it should act, which solutions it should adopt, let industries to better integrate and arrive at win-win state.

\section{Acknowledgments}

This research was supported by State general administration of sports philosophy and social sciences research project: based on "Internet+" the sport and tourism integration development path of research (project number: 2322SS16059).

\section{References}

1. J.L. Chang, Journal of Chengdu Physical Education Institute, 32, 5 (2006).

2. F.G. Jiang, Journal of Capital College of Physical Education, 17, 4 (2005).

3. B.L. Kang, Journal of Guilin Institute of Tourism, 4, 3 (2011).

4. W.W. Li, H.M. Wang, China Industrial Economy, 4 (2002).

5. C.B. Lu, R.H. Yu, Y.J. Duan, China Sport Science, 31, 9 (2011).

6. X.W. Ma, G. Guo, Z.N. Su, Sports \& Science, 322 (2011).

7. J. Song, Q.Z. Sun, H.J. Liu, China Sport Science and Technology, 465 (2010).

8. H.B. Liu, Z.L. Liu, Globalization Challenge and Management Transformation, I - III (2007).

9. J. Lee, D.H. Kim, S. Lee, Journal of Coastal Research, (2016). 